\title{
Application of Frequency Analysis on Peak River Discharge toward the Cumulative Floatable Litter Load at Log Boom Sungai Batu
}

\author{
Nur Khaliesah Abdul Malik ${ }^{1}$, Nor Rohaizah Jamil ${ }^{1}$, Latifah Abd Manaf ${ }^{1}$, Mohd Hafiz Rosli $^{1}$, Zulfa Hanan Ash'aari ${ }^{1}$, \\ and Fasihah Mohd Yusof ${ }^{1}$
}

${ }^{1}$ Department of Environmental Sciences, Faculty of Environmental Studies, Universiti Putra Malaysia (UPM), 43400 Serdang, Selangor, Malaysia

\begin{abstract}
The accumulation of floatable litter in the river is mainly influenced by the increasing number of human population, rapid urbanization and development which indirectly lead to the changes of hydrological processes in river discharge, decreasing the water quality and aesthetical value of the river. The main objective of this paper is to determine the cumulative floatable litter load captured at the log boom during the extreme events by using the Gumbel distribution method for frequency analysis in river discharge of Sungai Batu. The annual maximum river discharge for a period of 35 years (1982 to 2016) was used in Gumbel distribution method to obtain the discharge for different return period $(2,5,10,25,50,100$, and 200). The result shows that the estimated discharge $\left(103.17 \mathrm{~m}^{3} / \mathrm{s}\right)$ can estimate the cumulative floatable litter load (53267.27 kg/day) at 50 years return period. The $\mathrm{R}^{2}$ value obtained from non - linear regression analysis is 0.9986 indicate that Gumbel distribution is suitable to predict the expected discharge of the river. This study is very crucial for the related agencies in highlighting this environmental issues for their future references which can be used as a guidelines during the decision making process in making better improvement.
\end{abstract}

\section{Introduction}

The issue of floatable litter is very challenging in Malaysia as the accumulation of floatable litter in the river is mainly influenced by the rapid population growth, urbanization and development, indirectly resulted to the changes of hydrological processes in river discharge, decreasing the water quality and aesthetical value of the river as it is highly visible pollutant. Moreover, there are still limited studies on the floatable litter in the river [1-3] as compared to the marine litter studies due to the complexity in conducting the floatable litter assessment which requires a wide temporal integrative sampling method [4].

Floatable litter also has been described as the urban litter [5] which commonly found in the river due to fly tipping [4, 6]; littering activities and lack of policies integration between water and environmental management [7]; tourism activity [8]; inefficient of riverine litter management and maintenance [3] and lack of environmental awareness [7], subsequently becomes a major threat to the sustainability of environment, condition of socio - economic and public health. The accumulation of floatable litter also is mainly influenced by several factors such as physical characteristic of catchment [9-11]; land use types [6]; seasonality on climatic condition of rainfall pattern [11] and surface runoff $[4,12]$. Moreover, the propagation of floatable litter in the river can be diverse, depending on the classification types of buoyancy such as "persistent buoyant", "short-time buoyant", and "non-buoyant" [2]. The movement of floatable litter along the river is mainly transported by natural factor such as river flow condition [13-15] and wind [2, 16].

The Department of Irrigation and Drainage (DID) Malaysia has installed the log boom at the downstream area with low velocities of water $[16,17]$ as floatation structures to trap the highly buoyant materials [18] and subsequently mitigate the issue of propagation floatable litter in the river. However, the situation can become intense during the extreme events such as flood due to the high rainfall intensity which subsequently cause a large discharge [19]. The efficiency of $\log$ boom to capture the floatable litter is low during high flow condition [4] because material is overflow over and under the boom [20,21]. The floatable litters have high probabilities to overflow beyond the log boom capacity due to the large forces and inability of log boom to bypass high flows [18]. As a result, the propagation of floatable litter along the river will occurred until it sink or deposited at river bank or even transported towards the coastal area.

Corresponding author: norrohaizah@upm.edu.my 
Therefore, in such situation, the historical data of river discharge is considered for this study in determining the probability of events occurrence by using frequency analysis. This paper attempts to determine the cumulative floatable litter load captured at the log boom during the extreme events by using the Gumbel distribution method for frequency analysis on river discharge of Sungai Batu. The purpose of frequency analysis also can be applied in estimating the event magnitude value corresponding to the given return period [22]. The capability to determine the accumulation of floatable litter at $\log$ boom and predicting the extreme discharge is highly required as it can be a future references and guidelines for the related agencies such as solid waste management, river management and storm water management during the decision making process in making better improvement for their long-term planning.

\section{Materials and method}

\subsection{Study area}

The study was performed in Sungai Batu catchment which covered the small part of Selangor state at the south area (upstream) towards the Federal Territory of Kuala Lumpur (downstream) with an area approximately $103.50 \mathrm{~km}^{2}$ (Fig. 1). Sungai Batu has been surrounding with the highly intense of human population and rapid development areas such as residential area, commercial area and industrial area. The different types of socio economic condition and development can generate the different types of urban litter. Due to the intense anthropogenic human activities and other contributing factors in this area, DID has taken an effort in dealing this environmental issue by installing the log boom (Fig. 2) with the purpose to trap the highly buoyant and visible materials as a main target. The required catchment area to install the log boom, also known as Floating debris trap - Type 1 is normally more than 200 hectares [23].

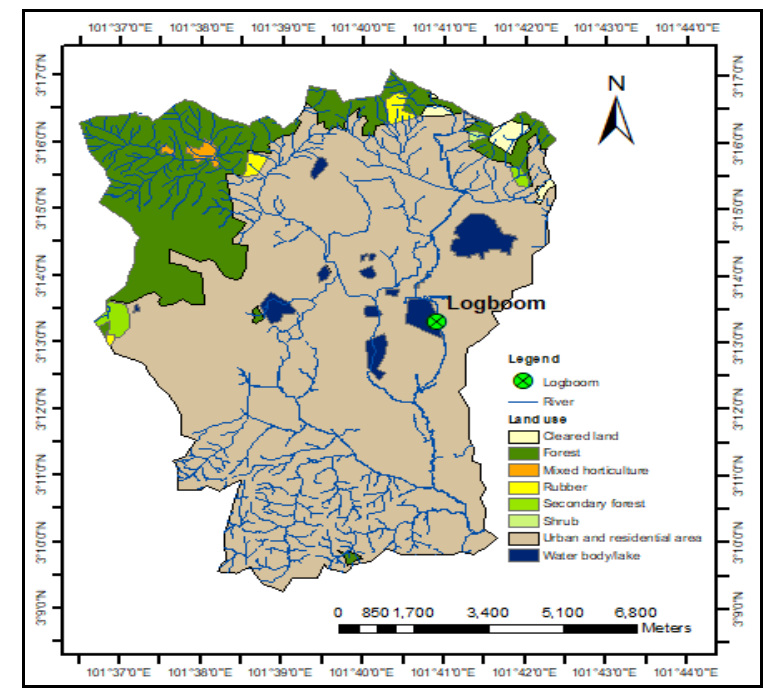

Fig. 1. The location of log boom (green circle) at downstream of Sungai Batu

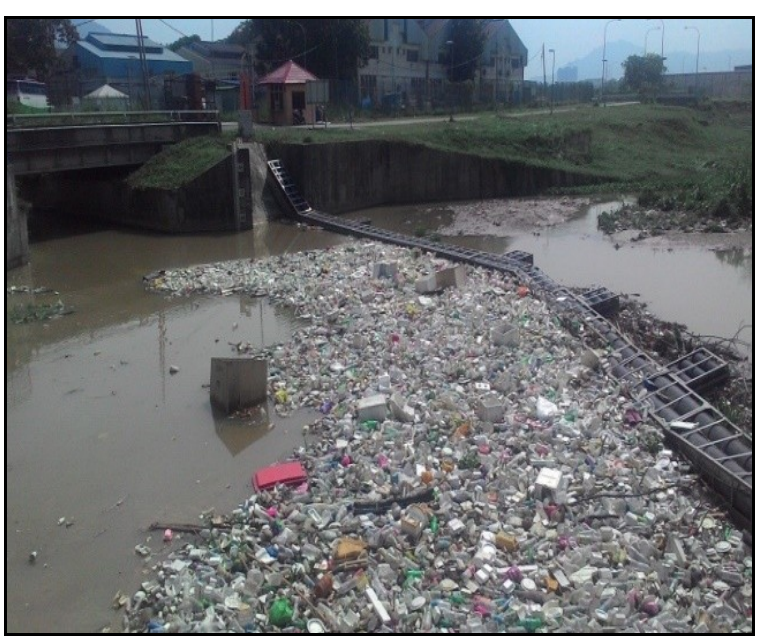

Fig. 2. The accumulation of floatable litter at log boom Sungai Batu

\subsection{Data collection and analysis}

The floatable litter collections have been conducted in 14 days during the operation day within the period from March to the end of April 2016 by using the bucket conveyer at sampling site. For the hydrological data, the maximum annual discharge data from 1982 - 2016 (35 years) was obtained from the DID, Malaysia. The methodological procedures to perform the frequency analysis by using Gumbel distribution function are beginning with the extraction of annual maximum value from the hydrologic time series data. The frequency analysis is the most crucial statistical tools to anticipate the probability of occurrence events in the future based on the provided historical data. The application of Gumbel distribution function known as Extreme Value Type I distribution function was performed for discharge as it is the most often statistical method used in predicting the extreme hydrological events [19, 22, 24]. The frequency discharge (in $\mathrm{m}^{3} / \mathrm{s}$ ) with specified return period $\left(\mathrm{X}_{\mathrm{T}}\right)$ for Gumbel distribution function is given by following equation:

$$
\mathrm{X}_{\mathrm{T}}=\bar{x}+\mathrm{K}_{\mathrm{T}} \cdot \sigma_{x}
$$

Where Gumbel frequency factor $\left(\mathrm{K}_{\mathrm{T}}\right)$ for method of adjustment was computed by using:

$$
\mathrm{K}_{\mathrm{T}}=-\frac{\sqrt{6}}{\pi}\left\{0.5772+\operatorname{In}\left[\operatorname{In} \frac{\tau}{\tau-1}\right]\right\}
$$

Where the statistical parameter of time series involving arithmetic average $(\bar{X})$, sample standard deviation $\left(\sigma_{x}\right)$ were computed by using:

$$
\begin{aligned}
& \bar{x}=\frac{1}{n} \sum_{i=1}^{n} x_{i} \\
& \sigma_{x}=\sqrt{\frac{1}{n-1} \sum_{i=1}^{n}\left(x_{i}-\bar{x}\right)^{2}}
\end{aligned}
$$




\section{Results and discussion}

\subsection{The relationship between cumulative floatable litter and cumulative discharge}

The relationship between cumulative floatable litter weight and cumulative discharge were derived from the 14 days of data collection during operation day which provide a useful qualitative picture of the impacts from land-based sources. The results show that the value coefficient of determination, $\mathrm{R}^{2}$ was 0.9663 indicate that $96.63 \%$ of the variation of cumulative discharge can be described by the variation of the cumulative floatable litter (Fig. 3). The graph also shows that the floatable litter increasing as the river flow increased which described that the accumulation of floatable litter at the $\log$ boom is mainly transported and controlled by the combination of water discharge. As an example based on the graph, the cumulative plot of floatable litter load shows that $29161.73 \mathrm{~kg} /$ day on days 14 was transported during period when discharge was $4.65 \mathrm{~m}^{3} / \mathrm{s}$. The floatable litter tends to accumulate and easily capture by the log boom during low flow condition and tend to overflow during high flow condition especially during extreme event. Therefore, the frequency analysis based on 35 years' data of river discharge data is performed for Sungai Batu.

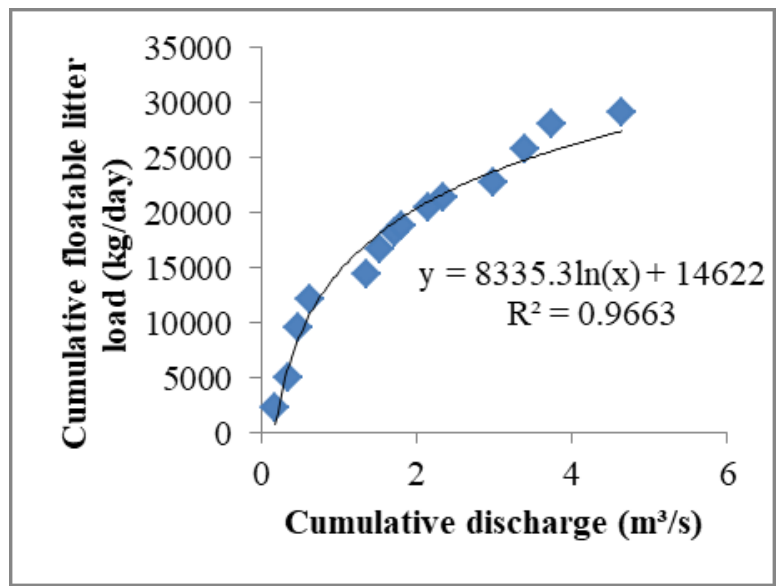

Fig. 3.The relationship between cumulative floatable litter load and cumulative discharge at log boom Sungai Batu

\subsection{Estimation of discharge and cumulative floatable litter load}

The estimation of maximum annual discharge for different return periods has been performed by using frequency analysis of river discharge through Gumbel distribution method as it is the most suitable model that can predict extreme event such as flood based on the historical data. The frequency of the discharge is generally described by the annual maximum series involving the largest observed values which indicate the extreme values within 35 years of discharge data.

According to the discharge plot at different return period developed by Gumbel distribution method for Sungai Batu, the discharge estimates are increasing with the increase of return periods (Fig. 4). In order to determine the estimation cumulative floatable litter load captured at log boom Sungai Batu, the computed estimated discharge from Table 1 have been inserted in derived equation; $\mathrm{y}=8335.3 \operatorname{In}(\mathrm{x})+14622$ and revealed the result of estimation cumulative floatable litter load captured at $\log$ boom Sungai Batu at different return period (Fig. 5). The result shows that the estimated cumulative floatable litter loads are increasing with the increase of return periods. The estimated discharge derived from the Gumbel distribution method was 28.70 $\mathrm{m}^{3} / \mathrm{s}, 52.58 \mathrm{~m}^{3} / \mathrm{s}, 68.38 \mathrm{~m}^{3} / \mathrm{s}, 88.35 \mathrm{~m}^{3} / \mathrm{s}, 103.17 \mathrm{~m}^{3} / \mathrm{s}$, $117.87 \mathrm{~m}^{3} / \mathrm{s}$ and $132.52 \mathrm{~m}^{3} / \mathrm{s}$ can estimate that the cumulative floatable litter load can reach up to 42603.73 $\mathrm{kg} /$ day, $47648.53 \mathrm{~kg} / \mathrm{day}, 49839.41 \mathrm{~kg} / \mathrm{day}, 51975.11$ $\mathrm{kg} /$ day, $53267.27 \mathrm{~kg} /$ day, $54378.00 \mathrm{~kg} /$ day and 55354.60 $\mathrm{kg} /$ day at $2,5,10,25,50,100$, and 200 years return period, respectively. However, the high value of discharge also may cause the overflow of floatable litter beyond the normal capacity of log boom. Therefore, in such situation, the frequency analysis of discharge is highly required to anticipate the future of extreme events based on the historical data.

Table 1. The computed discharge values and estimated cumulative floatable litter load captured at log boom for Sungai

Batu at different return periods using Gumbel distribution method

\begin{tabular}{|c|c|c|c|}
\hline $\begin{array}{c}\text { Return } \\
\text { period, } \\
\mathbf{T}_{\mathbf{r}}\end{array}$ & $\begin{array}{l}\text { Frequency } \\
\text { factor, } K_{t}\end{array}$ & $\begin{array}{c}\text { Discharge, } \\
\mathbf{X}_{\mathrm{T}}=\bar{X}+ \\
\mathbf{K}_{\mathrm{T}}, \sigma_{x}\end{array}$ & $\begin{array}{c}\text { Estimated } \\
\text { cumulative } \\
\text { floatable litter } \\
\text { load, } \\
y= \\
8335.3 \operatorname{In}(x)+ \\
14622\end{array}$ \\
\hline 2 & -0.164 & 28.70 & 42603.73 \\
\hline 5 & 0.719 & 52.58 & 47648.53 \\
\hline 10 & 1.305 & 68.38 & 49839.41 \\
\hline 25 & 2.044 & 88.35 & 51975.11 \\
\hline 50 & 2.592 & 103.17 & 53267.27 \\
\hline 100 & 3.137 & 117.87 & 54378.00 \\
\hline 200 & 3.679 & 132.52 & 55354.60 \\
\hline
\end{tabular}

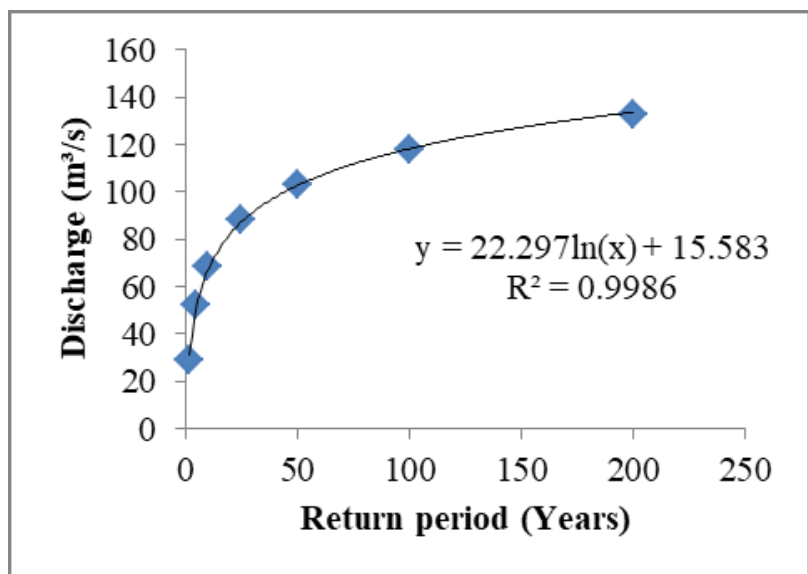

Fig. 4. The discharge plot at different return period developed by Gumbel distribution method for Sungai Batu 


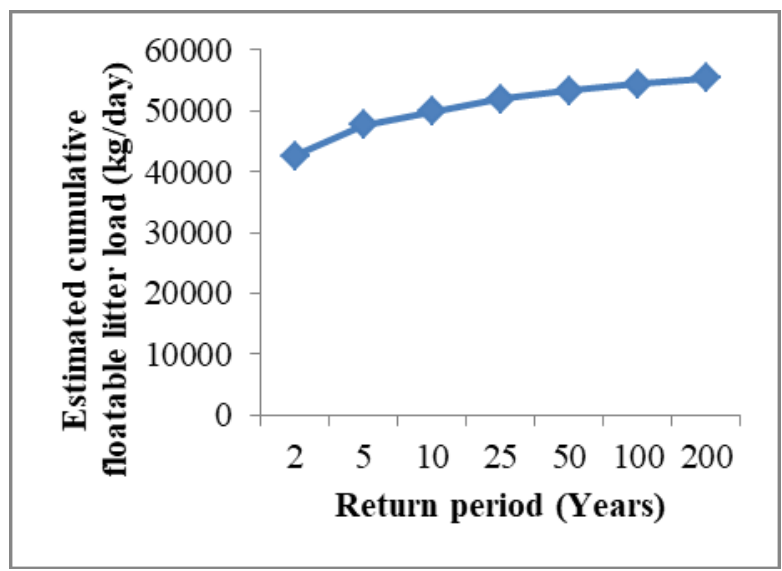

Fig. 5. The estimation cumulative floatable litter load captured at $\log$ boom Sungai Batu at different return period based on derived equation; $\mathrm{y}=8335.3 \operatorname{In}(\mathrm{x})+14622$

\section{Conclusions}

The accumulation of floatable litter captured at the log boom Sungai Batu is generally derived from various factors such as littering activities and illegal dumping into the river. The floatable litter is mainly transported toward the downstream of river by flow discharge. However, the log boom has been installed by DID to capture the floatable litter from being propagate until it reaches up to the coastal area. The frequency analysis based on the maximum annual discharge data from 1982 - 2016 (35 years) by using Gumbel distribution method have been successfully conducted by following the equation accordingly. The result shows that the estimated discharge and cumulative floatable litter load are increasing with the increase of return periods. As for example, the estimated discharge derived from the Gumbel distribution method was $103.17 \mathrm{~m}^{3} / \mathrm{s}$ can estimate that the cumulative floatable litter load can reach up to $53267.27 \mathrm{~kg} /$ day at 50 years return period. The $\mathrm{R}^{2}$ value obtained from non - linear regression analysis is 0.9986 indicate that the Gumbel distribution is suitable to predict the expected discharge of the river. Therefore, in such situation, the frequency analysis of discharge is highly required to anticipate the future of extreme events based on the historical data and can be applied to estimate the accumulation of floatable litter load captured at log boom as a guidelines and references for the related authorities and stakeholder during the decision making process.

The authors would like to acknowledge the Department of Irrigation and Drainage (DID), Malaysia for providing the valuable technical support in hydrological data throughout this project.

\section{References}

1. C.E. Balas, A.T. Williams, S. L. Simmons, A. Ergin, Mar. Pollut. Bull., 42, 1169 (2001)

2. S. Rech, V. Macaya-Caquilpán, J. F. Pantoja, M. M. Rivadeneira, D. Jofre Madariaga, M. Thiel, Mar. Pollut. Bull., 82, 66 (2014)
3. N. K.A. Malik, L.A. Manaf, J. Mater. Cycles Waste Manag., 20, 1063 (2018)

4. J. Gasperi, R. Dris, T. Bonin, V. Rocher, B. Tassin, Environ. Pollut., 195, 163 (2014)

5. N. Armitage, International Workshop on Global Developments in Urban Drainage Management, Indian Institute of Technology, Bombay, Mumbai India, 28 (2003)

6. A.T. Williams, S.L. Simmons, Water Air Soil Pollut., 112, 197 (1999)

7. B. Franz, M.A.V. Freitas, WIT Trans. Ecol. Envir., 167, 321, (2012)

8. S. S. Sadri, R. C. Thompson, Mar. Pollut. Bull., 81, 55 (2014)

9. N. Armitage, Rooseboom, A. Water SA, 26, 189 (2000)

10. L. Sidek, H. Basri, L. K. Lee, K. Y. Foo, Desalin. Water Treat., 57, 24733 (2016)

11. A.R. McCormick, T.J. Hoellein, Limnol. Oceanogr., 61, 1718 (2016)

12. M. Z. Alam, A. H. M. F. Anwar, D. C. Sarker, A. Heitz, C. Rothleitner, Sci Total Environ, 586, 76 (2017)

13. R. Allison, F. Chiew, T. McMahon, Stormwater Gross Pollutants, Cooperative Research Centre for Catchment Hydrology, (1997)

14. A.T. Williams, S.L. Simmons, Water Air Soil Pollut., 98, 119 (1997)

15. F. Galgani, J. P.Leaute, P. Moguedet, A. Souplet, Y. Verin, A. Carpentier, H. Goraguer, D. Latrouite, B. Andral, Y. Cadiou, J.C. Mahe, J.C. Poulard, P. Nerisson, Mar. Pollut. Bull., 40, 516 (2000)

16. B. Fitzgerald, W.S. Bird, Gross pollutant traps as a stormwater management practice, (2011)

17. R. A. Allison, T. A. Walker, F. H. S. Chiew, I. C. O. Neill, T.A. Mcmahon, R. Angus, From roads to rivers gross pollutant removal from urban waterways, Cooperative Research Centre for Catchment Hydrology, (1998)

18. L. Department of Planning, Chapter 9 Gross Pollutant Traps. Water Sensitive Urban Design Technical Manual for Greater Adelaide Region, 1 (2010)

19. S. Syafalni, O. Setyandito, F.R. Lubis, Y. Wijayanti, IJAER, 10, 9935 (2015)

20. Gamtron Pty Ltd, Performance Assessment of Four Rubbish Interception Booms, prepared for Water Board, Southern Region Stormwater Management, Rockdale, NSW (1992)

21. P.R. Horton, R.J. Cox, D.L. Wilkinson, 'Stormwater boom performance assessment and enhancement', Proceedings of the 16th Australian Water and Wastewater Association Federal Convention, (1995)

22. M. Alam, K. Emura, C. Farnham, J. Yuan, Climate, 6, 9 (2018)

23. Jabatan Pengairan dan Saliran. Urban stormwater management for Malaysia: MSMA 2nd Edition, (2012)

24. N. Bhagat, WROS, 6, 51 (2017) 